\title{
Genetic diversity of Plasmodium falciparum isolates from Pahang, Malaysia based on MSP-1 and MSP-2 genes
}

\author{
Wahib M Atroosh ${ }^{1 *}$, Hesham M Al-Mekhlafi ${ }^{1,3^{*}}$, Mohammed AK Mahdy ${ }^{1,3}$, Riyadh Saif-Ali ${ }^{2,4}$,
} Abdulsalam M Al-Mekhlafi, ${ }^{1,3}$ and Johari Surin ${ }^{1}$

\begin{abstract}
Background: Malaria is still a public health problem in Malaysia especially in the interior parts of Peninsular Malaysia and the states of Sabah and Sarawak (East Malaysia). This is the first study on the genetic diversity and genotype multiplicity of Plasmodium falciparum in Malaysia.

Methods: Seventy-five P. falciparum isolates were genotyped by using nested-PCR of MSP-1 (block 2) and MSP-2 (block 3).

Results: MSP-1 and MSP-2 allelic families were identified in 65 blood samples. RO33 was the predominant MSP-1 allelic family identified in $80.0 \%$ (52/65) of the samples while K1 family had the least frequency. Of the MSP-2 allelic families, 3D7 showed higher frequency (76.0\%) compared to FC27 (20.0\%). The multiplicity of $P$. falciparum infection (MOI) was 1.37 and 1.20 for MSP-1 and MSP-2, respectively. A total of seven alleles were detected; of which three MSP-1 allelic families (RO33, MAD20 and K1) were monomorphic in terms of size while MSP-2 alleles were polymorphic (two 3D7 and two FC27). Heterozygosity $\left(H_{E}\right)$ was 0.57 and 0.55 for MSP-1 and MSP-2, respectively.

Conclusions: The study showed that the $\mathrm{MOI}$ of $P$. falciparum is low, reflected the low intensity of malaria transmission in Pahang, Malaysia; RO33 and 3D7 were the most predominant circulating allelic families. The findings showed that $P$. falciparum has low allelic diversity with a high frequency of alleles. As a result, antimalarial drug efficacy trials based on MSP genotyping should be carefully interpreted.
\end{abstract}

\section{Background}

Malaria has been a global health problem threatening more than $40 \%$ of the world's population, and about $300-$ 500 million cases of malaria infection are reported every year with approximately one million deaths, mostly among children and pregnant women [1]. Among the malarial parasites, Plasmodium falciparum, causes the most severe malarial attacks, is responsible for the high morbidity and mortality, frequent antimalarial drug resistance and aborted vaccines trials $[2,3]$.

Genetic diversity determines the intensity of malaria transmission, thus providing baseline data for any

\footnotetext{
* Correspondence: wahib_atrosh@yahoo.com; halmekhlafi@yahoo.com 'Department of Parasitology, Faculty of Medicine, University of Malaya, Kuala Lumpur 50603, Malaysia

Full list of author information is available at the end of the article
}

antimalarial drug efficacy trial and the possibility of implementing control strategies based on vaccines. Merozoite surface proteins 1 and $2(M S P-1$ and $M S P-2)$ are widely used to study the allelic diversity and frequency of $P$. falciparum which are most commonly correlated with the level of transmission in the area under study. The two loci have also been introduced as a discriminatory tool to distinguish new from recrudescent infections $[4,5]$.

Despite the tremendous reduction in malaria annual cases achieved by The Malaria Control Programme (from 55,000 in 1990 to 7010 cases by 2009), malaria continues to be a public health problem in Malaysia, especially in rural and remote areas with $P$. falciparum, the most virulent species, accounting for more than one third of the reported malaria cases (Annual Reports, Ministry of Health, Malaysia). Information about the genetic diversity

\section{Biomed Central}

(c) 2011 Atroosh et al; licensee BioMed Central Ltd. This is an Open Access article distributed under the terms of the Creative Commons Attribution License (http://creativecommons.org/licenses/by/2.0), which permits unrestricted use, distribution, and reproduction in any medium, provided the original work is properly cited. 
of $P$. falciparum is lacking in Malaysia. This information is necessary for implementing PCR-based antimalarial drug efficacy trials to examine the current drug policy. Genotyping $P$. falciparum in the antimalarial drug efficacy trials prevents unnecessary change of drug policy due to misclassification of re-infection in the follow-up investigation as recrudescence. The discriminatory power of the genotyping method depends on the allelic diversity and frequency of $P$. falciparum in the study area. Thus, the present study was carried out to investigate the genetic diversity of $P$. falciparum isolated from Pahang, Malaysia using merozoite surface protein-1 (MSP-1) and merozoite surface protein-2 (MSP-2).

\section{Methods}

\section{Sampling and malaria microscopy}

A total of 822 blood samples were collected from different districts of Pahang, Malaysia (Figure 1); 728 samples by a survey and 64 by archived positive falciparum malaria slides. In the survey, a finger prick blood sample was taken from each subject for thick and thin blood film and 2-3 drops were collected on $3 \mathrm{MM}$ Whatman ${ }^{\circledR}$ filter paper (Whatman International Ltd., Maidstone, England). Blood films were stained with diluted Giemsa stain and then examined microscopically for the presence of malaria parasites; 200 fields under 1000× magnification were examined from the thick film before the slide was considered negative.

For positive slides, parasite species and stages were reported and parasitaemia (parasite density) was determined by counting only the asexual stages against 300 white blood cells (WBC) and then multiplied by 25 ; assuming the average of total WBC count of individuals equal to 7500 cells per $\mu$ l of blood [6]. The level of parasitaemia was graded as low (< 1000 parasites/ $\mu$ l of blood), moderate (1000 - 9999 parasites/ $\mu$ l of blood) and severe ( $\geq 10,000$ parasites/ $\mu$ l of blood). Archived malaria positive slides were also re-examined; parasite species and parasitaemia were recorded. All positive cases of single and mixed falciparum infections were considered for the molecular technique processing.

\section{Molecular identification and genotyping}

Genomic DNA was extracted from blood spots collected on filter papers and from archived Giemsa blood smears. Briefly, a disc of the filter paper was punched out from the blood spot using a pre-flamed paper puncher and placed in $1.5 \mathrm{ml}$ centrifuge tubes using clean, flamed forceps. Regarding archived slides, the slides were first cleaned with chloroform to remove oil. Then, $50 \mathrm{ml}$ of TE buffer was transferred onto the smear and at least half of the smear was completely wiped off the slide using Whatman 1 filter paper and transferred into $1.5 \mathrm{ml}$ microcentrifuge tubes. Genomic DNA was extracted using Qiagen blood and tissue kit (QIAGEN, DNeasy ${ }^{\circledR}$ Blood \& Tissue Kit, Cat. no. 69506, Germany) according to the manufacurer's instruction. DNA was eluted using 50 uL AE (10 mM Tris-Cl; 0.5 mM EDTA; pH 9.0) elution buffer (QIAGEN, DNeasy ${ }^{\circledR}$ Blood \& Tissue Kit, Cat. no. 69506 , Germany) and kept at $-20^{\circ} \mathrm{C}$ until used for PCR. Plasmodium spp were identified by $18 \mathrm{~s}$ rRNAbased nested PCR using genus- and species - specific primers as mentioned previously [7].

$P$. falciparum were further analyzed by amplification of the two highly polymorphic regions of $M S P-1$ (Block 2) and MSP-2 (Block 3) using nested-PCR as mentioned previously [8], with slight modifications for the cycling conditions of the secondary PCR. Briefly, oligonucleotide primers sets (Table 1), previously designed by Snounou et al. [8], were used for detecting the different families (K1, MAD20 and RO33 in MSP-1; FC27 and 3D7 in $M S P-2)$. In the primary PCR, a $50 \mu \mathrm{l} \mathrm{PCR} \mathrm{mixture} \mathrm{was}$ used containing $5 \mu \mathrm{l}$ of DNA extract, $1 \mathrm{X}$ of $\mathrm{MgCl} 2$ free buffer, $1 \mathrm{mM}$ of $\mathrm{MgCl}_{2}, 125 \mu \mathrm{M}$ of dNTPs, $250 \mathrm{mM}$ of each primer and 1.25 of Taq polymerase enzyme. All reagents were from iNtRON (iNtRON Biotechnology, Inc. Seoul, Korea). Cycling conditions for the primary PCR were as follows; starting with three single steps of denaturation at $94^{\circ} \mathrm{C}$ for 5 minutes, annealing at $58^{\circ} \mathrm{C}$ for 2 minutes and extension at $72^{\circ} \mathrm{C}$ for 2 minutes. This is followed by 25 cycles of denaturation at $94^{\circ} \mathrm{C}$ for $1 \mathrm{~min}$ ute, annealing at $58^{\circ} \mathrm{C}$ for 2 minutes and extension at $72^{\circ} \mathrm{C}$ for 2 minutes, then a single annealing step at $58^{\circ} \mathrm{C}$ for 2 minutes and final extension at $72^{\circ} \mathrm{C}$ for 5 minutes. Three $\mu$ of primary PCR product were used as a DNA template in the secondary PCR which had similar concentrations to the primary PCR. The cycling conditions for the secondary PCR were as follows: starting with a single step of denaturation at $95^{\circ} \mathrm{C}$ for 10 minutes followed by 40 cycles of denaturation at $94^{\circ} \mathrm{C}$ for $30 \mathrm{sec}-$ onds, annealing at $58^{\circ} \mathrm{C}$ for 30 seconds and extension at $72^{\circ} \mathrm{C}$ for 1 minute, and a final extension at $72^{\circ} \mathrm{C}$ for 10 minutes. PCR reaction mixtures were incubated in a thermal cycler (MyCycler-BioRad, Hercules, USA).

\section{Detection of Alleles}

The secondary PCR products were separated by electrophoresis on $7 \%$ polyacrylamide gel in $1 \mathrm{X}$ TBE (Trisborate EDTA) buffer stained with ethidium bromide. Bands were visualized by the gel document system (Infinity 3026, Vilber Lourmat, Marnela Valled, France) and the sizes of the fragments were estimated by comparison to the 100 bp DNA ladder (iNtRON Biotechnology, Inc. Seoul, Korea). Fragments representing the different alleles were selected and purified using a PCR purification kit (iNtRON Biotechnology, MEGAquick-spin PCR 


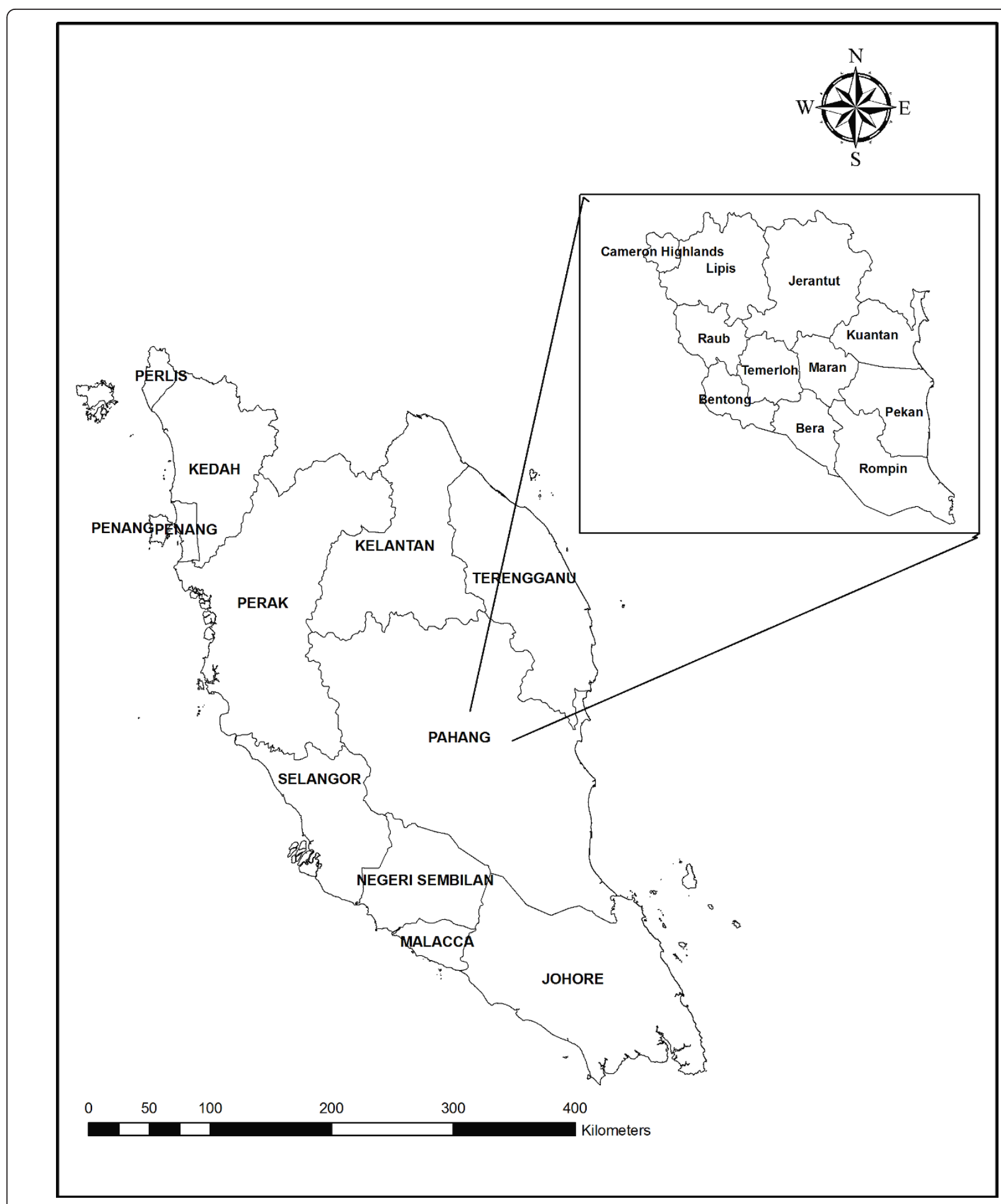

Figure 1 A geographic map showing Peninsular Malaysia and Pahang's districts.

\& Agarose Gel DNA Extraction System, Cat. no. 17281, Seoul, Korea). Purified PCR products for a limited number of isolates representing different alleles of MSP-1 and $M S P-2$ were sequenced in both directions with the primers of the secondary PCR using the ABI PRISM ${ }^{\circledR}$ BigDyeTM terminator v3.0 Ready Reaction Cycle Sequencing Kit according to the manufacurer's instruction (Applied Biosystems, USA) in $3130 \times 1$ Genetic 
Table 1 Sequences of the primers used to amplify the MSP-1 and MSP-2 genes of $P$. falciparum isolates from Pahang, Malaysia

\begin{tabular}{|c|c|c|}
\hline Amplification/Gene & Primer & Primer sequence \\
\hline \multicolumn{3}{|l|}{ Primary PCR } \\
\hline \multirow[t]{2}{*}{ MSP-1 } & M1-OF & $5^{-}$-CTAGAAGCTITAGAAGATGCAGTATTG-3 \\
\hline & $\mathrm{M} 1-\mathrm{OR}$ & $5^{-}$-CTTAAATAGTATTCTAATTCAAGTGGATCA-3- \\
\hline \multirow[t]{2}{*}{ MSP-2 } & M2-OF & $5^{-}$-ATGAAGGTAATTAAAACATTGTCTATTATA-3- \\
\hline & M2-OR & $5^{-}$-CTITGTTACCATCGGTACATTCTT-3- \\
\hline \multicolumn{3}{|l|}{ Secondary PCR } \\
\hline \multirow[t]{6}{*}{ MSP-1 } & $\mathrm{M} 1-\mathrm{KF}$ & $5^{-}$-AAATGAAGAAGAAATTACTACAAAAGGTGC-3- \\
\hline & $M 1-K R$ & $5^{-}$-GCTTGCATCAGCTGGAGGGCTTGCACCAGA-3- \\
\hline & M1-MF & $5^{-}$-AAATGAAGGAACAAGTGGAACAGCTGTTAC-3- \\
\hline & M1-MR & $5^{-}$-ATCTGAAGGATTTGTACGTCTTGAATTACC-3- \\
\hline & M1-RF & $5^{-}$-TAAAGGATGGAGCAAATACTCAAGTTGTTG-3- \\
\hline & M1-RR & $5^{-}$-CATCTGAAGGATTTGCAGCACCTGGAGATC-3- \\
\hline \multirow[t]{4}{*}{ MSP-2 } & M2-FCF & $5^{-}$-AATACTAAGAGTGTAGGTGCARATGCTCCA-3- \\
\hline & M2-FCR & $5^{-}$-TTTATTTGGTGCATTGCCAGAACTTGAAC-3- \\
\hline & M2-ICF & $5^{-}$-AGAAGTATGGCAGAAAGTAAkCCTYCTACT-3- \\
\hline & $M 2-I C R$ & $5^{-}$-GATTGTAATTCGGGGGATTCAGTTGTTCG-3- \\
\hline
\end{tabular}

Analyzer (Applied Biosystems, USA). The sequences were used to correct the estimated molecular weight and to confirm the nature of the amplified product.

\section{Multiplicity of infection and heterozygosity}

The multiplicity of infection (MOI) or number of genotypes per infection was calculated by dividing the total number of fragments detected in MSP-1 or MSP-2 by the number of samples positive for the same marker. Heterozygosity which represents the probability of being infected by two parasites with different alleles at a given locus and ranging between 0 and 1 was calculated by using the following formula: $\mathrm{H}_{\mathrm{E}}=[\mathrm{n} /(\mathrm{n}-1)]\left[\left(1-\sum \mathrm{pi}^{2}\right)\right]$, where $\mathrm{n}$ is the number of isolates sampled and pi is the allele frequency at a given locus [5,9]. Isolates with more than one genotype were considered as polyclonal infection while the presence of a single allele was considered as monoclonal infection.

\section{Statistical analysis}

Data was analyzed using the SPSS for windows software version 13. For descriptive analysis, proportion was used to present the distribution of different allelic families while the mean was used to present the MOI. Independent $\mathrm{t}$-test was used to compare the mean MOI according to gender, time of the year of infection and parasitaemia. A $P$ value of $\leq 0.05$ was considered indicative of a statistically significant difference.

\section{Ethical consideration}

The protocol of this study (Reference Number: 788.73) has been approved by the Medical Ethics Committee of the University of Malaya Medical Centre, Kuala Lumpur,
Malaysia. The study was also registered with the National Medical Research Registry, Malaysia (Research ID: 5681). After a clear explanation of the objectives of the study, the subjects concerned agreed to participate in the study and verbal consents were obtained.

\section{Results}

P. falciparum parasites were detected in a total of 75 samples. This includes 64 archived positive slides, and eleven blood samples out of 728 collected in the survey. Of the total positive samples, $66 \%$ were from males and $34 \%$ were from females with a mean age of 27.8 years and standard deviation of 4.1 years. Moreover, $64.2 \%$ of the positive samples collected were from Malay, $23.9 \%$ from aborigines, $6.5 \%$ from Indians and $2.7 \%$ from Chinese. In addition, two cases were detected from foreign workers who were residing in Malaysia for the past three years. The asexual P. falciparum parasitaemia from the collected samples ranged from 50 to 17,100 parasites/ $\mu$ l of blood with a geometric mean of 4,065 parasites $/ \mu$ l. Low parasitaemic individuals (parasite count $<1000$ parasites/ $\mu$ l of blood) represented $41.3 \%$, while moderate-to-high parasitaemia (parasite count $\geq$ 1000 parasites $/ \mu \mathrm{l}$ of blood) were $58.7 \%$.

\section{Multiplicity of infection and genetic diversity}

All samples positive for $P$. falciparum were genotyped using MSP-1 (Block-2) and MSP-2 (Block-3) by nested PCR. Of these, 65 (87\%) were found positive for $M S P-1$ and MSP-2 (40 with MSP-1only and 25 with both). Multiplicity of infection (MOI) was found to be 1.37 and 1.20 for $M S P-1$ and $M S P-2$, respectively (Table 2). Mean MOI was compared according to parasitaemia (low and 
Table 2 Multiplicity of infection, heterozygosity and type of infection for MSP-1 and MSP-2 genes of $P$. falciparum isolates from Pahang, Malaysia

\begin{tabular}{ccccc}
\hline Gene & $\begin{array}{c}\text { MOI } \\
\text { Mean }( \pm \text { SEM) }\end{array}$ & Heterozygosity & $\begin{array}{c}\text { Monoclonal infection } \\
\mathbf{n}(\%)\end{array}$ & $\begin{array}{c}\text { Polyclonal infection } \\
\mathbf{n}(\%)\end{array}$ \\
\hline MSP-1 & $1.37( \pm 0.1)$ & 0.57 & $43(66.2)$ & $22(33.8)$ \\
\hline MSP-2 & $1.20( \pm 0.09)$ & 0.55 & $20(80.0)$ & $5(20.0)$ \\
\hline
\end{tabular}

$\mathrm{n}$ : number of cases. SEM: standard error of mean

moderate-to-high), year of infection (2007/2008 and 2009/2010) and sex of patients. The mean MOI was found to be higher in female patients, those diagnosed in year 2009/2010, and in individuals with moderate-tohigh parasitaemia than male patients, those diagnosed in year $2007 / 2008$, and in those with low parasitaemia. However, the differences in MOI between these groups were not statistically significant $(\mathrm{P}>0.05)$.

In MSP-1, RO33, MAD20 and K1 allelic families were identified with an overall frequency of 89 . RO33 allelic family was predominant as it was identified in $80.0 \%$ $(52 / 65)$ of the samples. The distribution of the identified MSP-1 allelic families is illustrated in Figure 2. One third (33.8\%) of the blood samples positive for MSP-1 were identified as polyclonal infections while two-thirds (66.2\%) were monoclonal infections. Among the polyclonal infections, RO33/MAD20 and RO33/K1 constituted $18.5 \%(12 / 65)$ and $10.8 \%(7 / 65)$, respectively. Trimorphic infections of MSP-1, ie. those having three allelic families, were also reported in $3.1 \%$ of the cases. With respect to MSP-2, 3D7 and FC27 allele types were detected among the isolates (Figure 3). The frequency of samples with only 3D7 allelic family [76.0\% (19/25)] was found to be higher than the samples with only FC27 family [20.0\% (5/25)]. However, MSP-2 with both allelic types was identified only in one sample (4.0\%). On the other hand, monoclonal

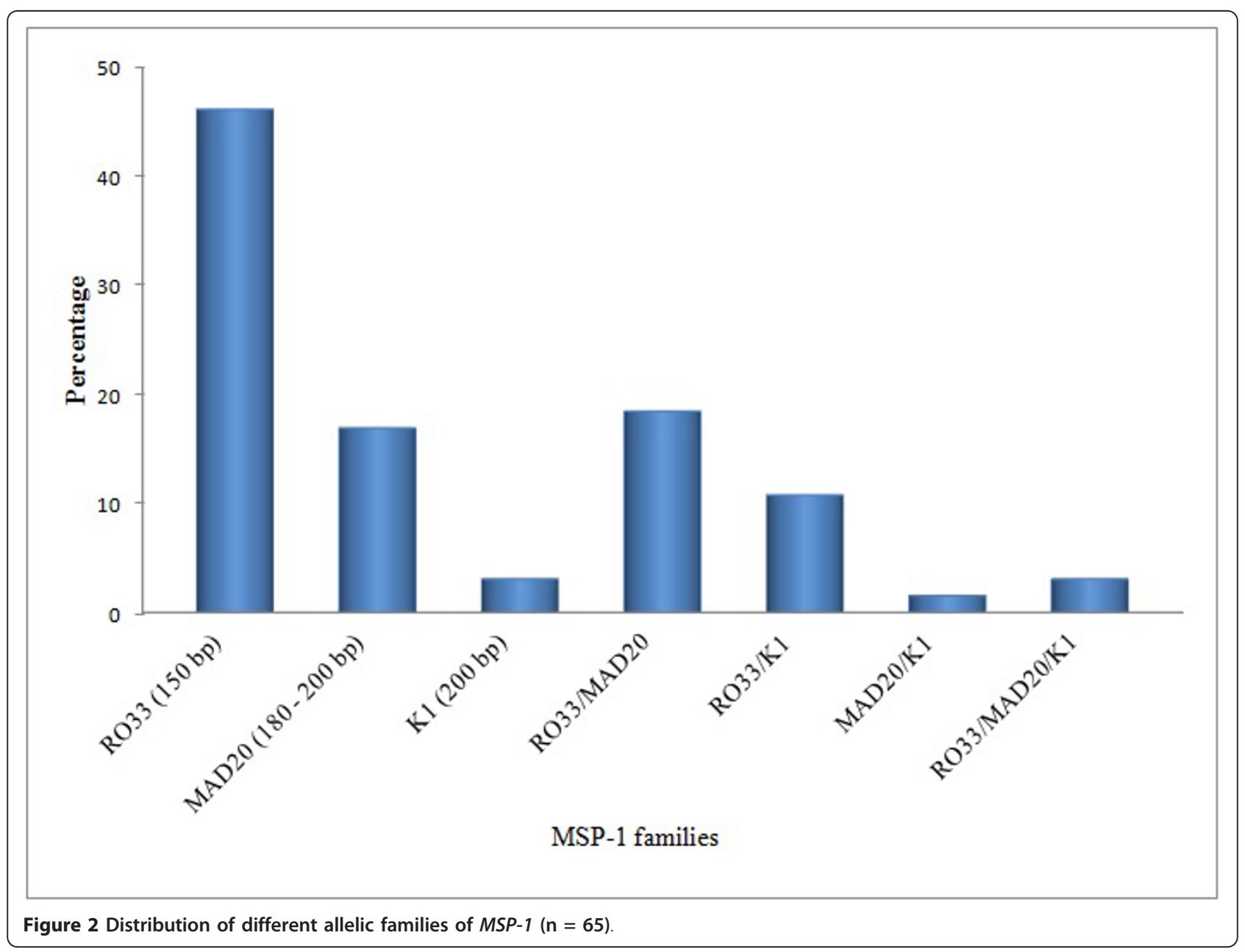




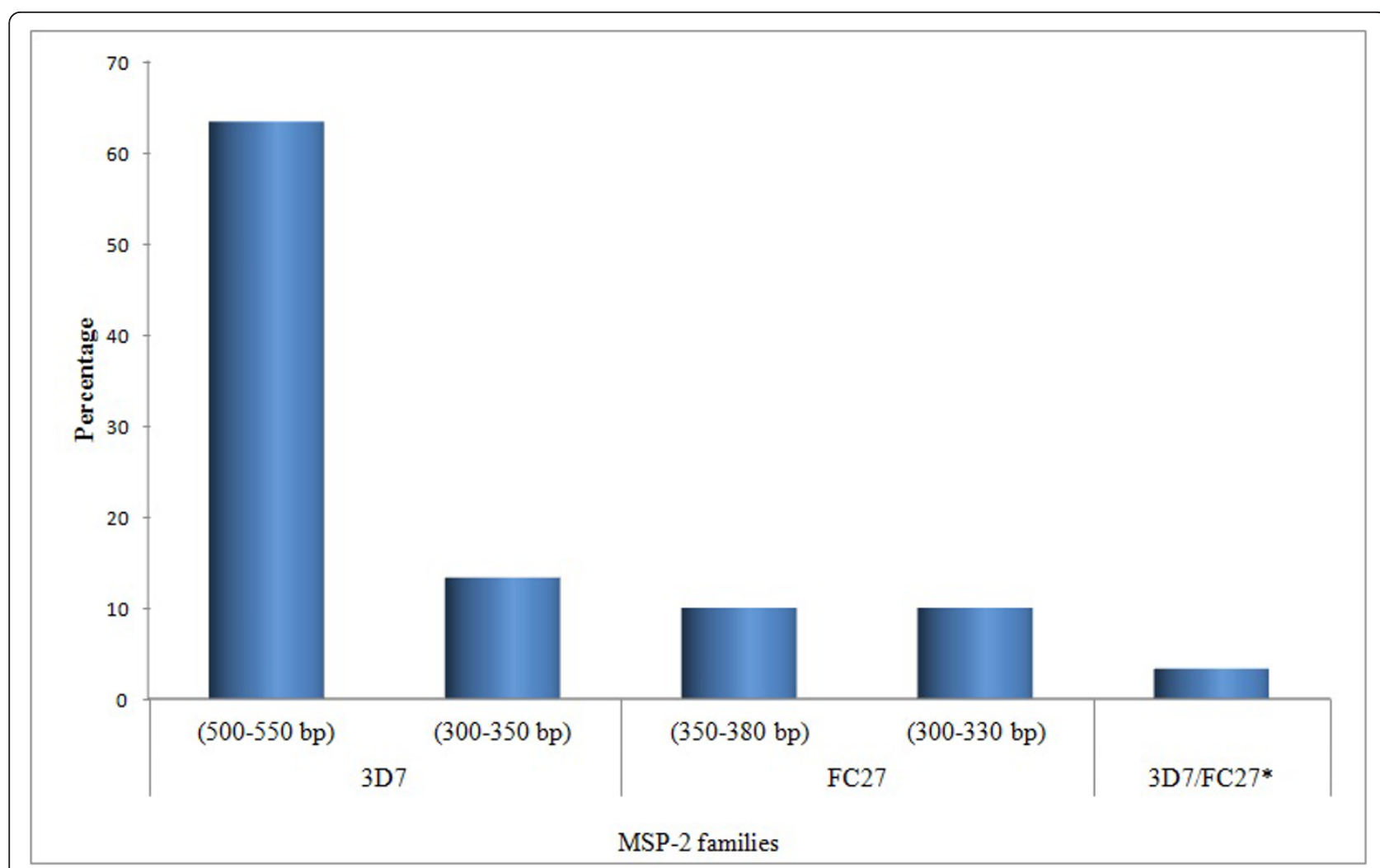

Figure 3 Distribution of different allelic families of $\mathbf{M S P}-\mathbf{2}(\mathbf{n}=\mathbf{2 5})$ * $3 \mathrm{D} 7$ (300-350 bp)/FC27 (350-380 bp).

infection was reported in $80.0 \%(20 / 25)$ of cases positive for $M S P-2$ alleles while $20 \%$ were polyclonal.

\section{Allelic frequency and heterozygosity}

The total number of detected alleles was seven. MSP-1 had three alleles; RO33 (150 bp), MAD20 (180 - 200 bp) and K1 (200 bp). Within MSP-2 block, 3D7 family had two different alleles; 3D7 (330 - $350 \mathrm{bp)}$ and 3D7 (500 $550 \mathrm{bp}$ ). Similarly, two different alleles were detected for FC27 family; FC27 (300 - 330 bp) and FC27 (350 - 380 bp). The frequencies of these alleles based on PCR products size (base pairs, bp) and their combinations are shown in Figures 2 and 3. Expected heterozygosity was almost the same for MSP-1 locus $\left(\mathrm{H}_{\mathrm{E}}=0.57\right)$ and $M S P-2$ locus $\left(\mathrm{H}_{\mathrm{E}}=0.55\right)$.

\section{Discussion}

The present study is the first to provide information about the genetic diversity of $P$. falciparum in Malaysia. Our findings showed a low multiplicity of infection (MOI) for both $M S P-1$ and $M S P-2$ reflecting the low intensity of malaria transmission in Peninsular Malaysia. This is in agreement with previous observations of an increased MOI with increasing endemicity $[10,11]$.

The present study showed that the frequency of the $M S P-1$ allelic families was higher than $M S P-2$. The predominant families in the $M S P-1$ and $M S P-2$ were RO33 and 3D7, respectively. These findings are in agreement with previous studies in Brazil and Gabon which demonstrated the predominance of the RO33 allelic family $[12,13]$. By contrast, previous studies in Thailand and Myanmar showed that MAD20 was the predominant allelic family while RO33 family showed either a very low frequency or not detected at all $[8,14]$. A topographic-based variation in the distribution of MSP-1 allelic families within the same area was described by a recent study from Indonesia which aimed at comparing the distribution of MSP-1 allelic families in coastal and mountainous areas in West Sumatera. This study reported that $\mathrm{K} 1$ and MAD20 were the most predominant allelic families in the coastal and mountainous areas, respectively [15].

The association between the distribution of allelic families and the severity of malaria has been investigated, and the studies have yielded a variety of results. RO33 allelic family was frequently reported in asymptomatic malaria cases and K1 family in severe cases $[13,16]$. This is supported by a community-based study in Papua New Guinea which reported an association between reduced risk of clinical malaria and infection with parasites of MSP-1 type RO33 or MSP-2 type 3D7 [17]. Moreover, a study from Senegal showed that MSP-2 was found more 
prevalent among patients with severe malaria than $M S P$ 1 [18]. On the other hand, previous studies revealed an association between the dominance of $\mathrm{K} 1$ allelic family and the existence of asymptomatic malaria infection $[19,20]$. In this present study, we could not examine such association as the majority of samples were archived stained slides with unclear information on the severity of malaria infections. However, among the eleven positive blood samples collected by the survey, only one severe malaria case was reported. A previous community-based study which has been carried out in Pahang, Malaysia indicated that most of the malaria patients diagnosed during mass screening surveys conducted by malaria control units, were apparently healthy [21].

The present study found that about two-thirds of the MSP-1 positive cases harbored a single allele (monoclonal infection), and the polyclonal infection was reported in $33.8 \%$. On the other hand, $80.0 \%$ of the MSP-2 positive cases had monoclonal infection. These findings suggested a low complexity of $P$. falciparum population. Polyclonal type infections were found in the mesoendemic areas up to $50 \%$ as against $100 \%$ in holoendemic areas [20,22,23]. Moreover, a previous study from Congo showed a significant association between the complexity of infection and polyclonal infections with the asymptomatic malaria [24]. Another study aimed at comparing the genetic diversity (based on MSP-1) of malaria parasite in different countries of different endemicity levels showed that the presence of polyclonal infection was more common in areas with high endemicity [25].

The present study reported few numbers of alleles (seven alleles for both MSP-1 and MSP-2) circulating in the study area with RO33 (150 bp) and 3D7 (500 - 550 bp) being highly frequent. We found that MSP-2 allelic families 3D7 and FC27 exhibit size polymorphism while MSP-1 allelic families K1, MAD20 and RO33 showed monomorphic pattern. Previous studies reported that $M S P$-2 gene is highly polymorphic compared to MSP-1 and among the MSP-1 alleles, RO33 found to be monomorphic compared to the polymorphic families $\mathrm{K} 1$ and MAD20 [8,26]. Moreover, a previous study from a low endemic country identified only one MAD20 allele of MSP-1 while RO33 or K1 alleles were not found in any sample [27]. It is reported that genomic DNA extracted from archived stained blood slides showed a relatively poor performance at low level parasitaemia and this may explain the low detection of MSP-2 [28]. However, we should indicate that all blood samples collected by the survey were found to be positive for both $M S P-1$ and MSP-2.

The low allelic diversity together with the high frequency of the circulating alleles increase the chance of the re-infection with the same allele, decreasing the discriminatory power of $M S P-1$ and $M S P$ - 2 to differentiate between recrudescence and re-infection in Peninsular Malaysia. Thus, the genotyping of $P$. falciparum based on MSP-1 and MSP-2 in antimalarial drug efficacy trials, in Peninsular Malaysia, may lead to misclassification of re-infection as recrudescence (treatment failure) and cause unnecessary change of malaria drug policy. However, the possibility of re-infection during the follow-up may be low in an area with low intensity of transmission. In the same vein, heterozygosity was 0.55 0.57 suggesting that the parasite population in Pahang, Malaysia exhibits intermediate heterozygosity, which is consistent with the heterozygosity range (0.51-0.65) reported in Southeast Asia/Pacific region [29]. In areas with declining endemicity, it is reported that the number and diversity of alleles (heterozygosity) decrease with decreasing $P$. falciparum transmission $[29,30]$.

The correlation between the genetic variation of $P$. falciparum and malaria endemicity has been described $[10,11]$. Our findings showed no significant difference in the mean MOI according to sex of patients, level of parasitaemia, and years of infection. This is in agreement with previous reports in other countries [31,32]. In contrast, previous studies from Senegal, Mozambique and Iran showed a significantly high MOI in patients with moderate-to-high parasitaemia [33,34]. In the present study, most of the positive samples were from adult patients aged 22-40 years, and this limited range of age constraint examining the difference in MOI according to age. However, previous studies showed a pattern of greater MOI in older individuals than younger individuals reflecting more previous exposure to infection $[35,36]$. Conflicting findings, indicated decreased MOI with age, were also reported [32,37].

\section{Conclusions}

This study provides information on the genetic diversity of P. falciparum in Malaysia based of MSP-1 and MSP2. Malaria due to P. falciparum in Pahang state of Malaysia was found mostly to be monoclonal infection with generally low parasite diversity, together with high predominance of RO33 allelic family of MSP-1 and 3D7 family of $M S P-2$. The low allelic diversity with the high frequency of alleles may limit the use of MSP-based genotyping in antimalarial drug efficacy trials in Peninsular Malaysia.

\section{Acknowledgements}

The authors wish to acknowledge the cooperation of the Directors of Health Offices in the districts of Pahang, Mr. Mohd Mahir from the Vector Control Unit-Kuala Lipis and Mr. Shamsuddin bin Mohd Nasib from Pahang State Health Department. The authors would like to acknowledge Mr. Nazeh Alabd from Faculty of Science and Mr. Nabil Nasr from the Department of Parasitology, Faculty of Medicine, University of Malaya for their fruitful help during sample collection and laboratory work. We thank Mr. Romano Ngau 
from Department of Parasitology, University of Malaya for creating the map of the study area. This study was financially supported by the University of Malaya, Kuala Lumpur, Malaysia (Research grants codes RG151/09HTM \& PS224/2010A).

\section{Author details}

'Department of Parasitology, Faculty of Medicine, University of Malaya, Kuala Lumpur 50603, Malaysia. ${ }^{2}$ Department of Molecular Medicine, Faculty of Medicine, University of Malaya, Kuala Lumpur 50603, Malaysia. ${ }^{3}$ Department of Parasitology, Faculty of Medicine and Health Sciences, Sana'a University, Sana'a, Yemen. ${ }^{4}$ Department of Biochemistry, Faculty of Medicine and Health Sciences, Sana'a University, Sana'a, Yemen.

\section{Authors' contributions}

WMA, HMA, MAKM and JS designed the study; WMA and AMA the field study, carried out the laboratory work and collated the data; WMA and HMA performed the statistical analysis; MAKM and RSA provided technical advisory support in genotyping and data interpretation; WMA, HMA and MAKM drafted the primary version of the manuscript; JS and RSA contributed to the revision of the manuscript. All authors read and approved the final manuscript.

\section{Competing interests}

The authors declare that they have no competing interests.

Received: 14 June 2011 Accepted: 13 December 2011

Published: 13 December 2011

\section{References}

1. WHO: WHO World Malaria Report World Health Organization; 2010

2. Wongsrichanalai C, Pickard A, Wernsdorfer W, Meshnick S: Epidemiology of drug-resistant malaria. Lancet Infec Dis 2002, 2:209-218.

3. Kiwanuka GN: Genetic diversity in Plasmodium falciparum merozoite surface protein 1 and 2 coding genes and its implications in malaria epidemiology: a review of published studies from 1997-2007. J Vector Borne Dis 2009, 46:1-12.

4. Cattamanchi A, Kyabayinze D, Hubbard A, Rosenthal PJ, Dorsey G: Distinguishing recrudescence from reinfection in a longitudinal antimalarial drug efficacy study: comparison of results based on genotyping of msp-1, msp-2, and glurp. Am J Trop Med Hyg 2003, 68:133-139.

5. Mwingira F, Nkwengulila G, Schoepflin S, Sumari D, Beck H-P, Snounou G, Felger I, Olliaro P, Mugittu K: Plasmodium falciparum msp1, msp2 and glurp allele frequency and diversity in sub-Saharan Africa. Malar J 2011, 10:79.

6. Dicko A, Sagara I, Djimde AA, Toure SO, Traore M, Dama S, Diallo A, Barry A, Dicko M, Coulibaly OM, Rogier C, de Sousa A, Doumbo OK: Molecular markers of resistance to sulphadoxine-pyrimethamine one year after implementation of intermittent preventive treatment of malaria in infants in Mali. Malar J 2010, 9:9.

7. Al-Mekhlafi AM, Mahdy MA, Al-Mekhlafi HM, Azazy A, Fong MY: High frequency of Plasmodium falciparum chloroquine resistance marker (pfcrt T76 mutation) in Yemen: An urgent need to re-examine malaria drug policy. Parasit Vectors 2011, 4:94.

8. Snounou G, Zhu X, Siripoon N, Jarra W, Thaithong S, Brown KN, Viriyakosol S: Biased distribution of msp1 and $\mathrm{msp2}$ allelic variants in Plasmodium falciparum populations in Thailand. Trans $R$ Soc Trop Med Hyg 1999, 93:369-374.

9. Su XFM, Huang Y, Huynh CQ, Liu A, You J, Wooton J, Wellems TE: A genetic map and recombination parameters of the human malaria parasite Plasmdoium falciparum. Science 1999, 286:1351-1353.

10. Haddad D, Snounou G, Mattei D, Enamorado IG, Figueroa J, Stahl S, Berzins K: Limited genetic diversity of Plasmodium falciparum in field isolates from Honduras. Am J Trop Med Hyg 1999, 60:30-34.

11. Babiker HA, Ranford-Cartwright LC, Walliker D: Genetic structure and dynamics of Plasmodium falciparum infections in the Kilombero region of Tanzania. Trans R Soc Trop Med Hyg 1999, 93:11-14.

12. Kimura E, Mattei D, Mana di Santa S, Scherf A: Genetic diversity in the major merozoite surface antigen of Plasmodium falciparum high prevalence of a third polymorphic form detected in strains derived from malaria patients. Gene 1990, 91:57-62.
13. Kun FJJ, Schmidt-Ott RJ, Lehman LG, Lell B, Luckner D, Greve B, Matousek P, Kremsner PG: Merozoite surface antigen 1 and 2 genotypes and rosetting of Plasmodium falciparum in severe and mild malaria in Lambarene, Gabon. Trans R Soc Trop Med Hyg 1998, 92:110-114.

14. Kang J-M, Moon S-U, Kim J-Y, Cho S-H, Lin K, Sohn W-M, Kim T-S, Na B-K: Genetic polymorphism of merozoite surface protein-1 and merozoite surface protein-2 in Plasmodium falciparum field isolates from Myanmar. Malar J 2010, 9:131.

15. Irawati N: Genetic polymorphism of merozoite surface protein-1 (MSP-1) block 2 allelic types in Plasmodium falciparum field isolates from mountain and coastal area in West Sumatera, Indonesia. Med I Indones 2011, 20:11-14.

16. Ntoumi F, Mercereau-Puijalon O, Luty A, Georges A, Millet P: High prevalence of the third form of merozoite surface protein-1 in Plasmodium falciparum in asymptomatic children in Gabon. Trans $R$ Soc Trop Med Hyg 1996, 90:701-702.

17. Al-Yaman F, Genton B, Reeder JC, Anders RF, Smith T, Alpers MP: Reduced risk of clinical malaria in children infected with multiple clones of Plasmodium falciparum in a highly endemic area: a prospective community study. Trans R Soc Trop Med Hyg 1997, 91:602-605.

18. Robert F, Ntoumi F, Angel G, Candito D, Rogier C, Fandeur T, Sarthou JL, Mercereau-Puijalon O: Extensive genetic diversity of Plasmodium falciparum isolates collected from patients with severe malaria in Dakar, Senegal. Trans R Soc Trop Med Hyg 1996, 90:704-711.

19. Amodu OK, Adeyemo AA, Ayoola OO, Gbadegesin RA, Orimadegun AE, Akinsola AK, Olumese PE, Omotade OO: Genetic diversity of the msp-1 locus and symptomatic malaria in south-west Nigeria. Acta Trop 2005, 95:226-232.

20. Babiker HA: Plasmodium falciparum population in the unstable malaria area of eastern Sudan is stable and genetically complex. Trans $R$ Soc Trop Med Hyg 1998, 92:585-589.

21. Mahdy MAK, Chan BTE, Noor Hayati MI, Sa'iah HA, Ismail MG, Jeffery J: The distribution of malaria parasites among Orang Asli populations living in the interior areas of Pahang and Kelantan, Malaysia. Trop Biomed 2004, 21:101-105.

22. Paul REL, Day KP: Mating patterns of Plasmodium falciparum. Parasitol Today 1998, 14:197-202.

23. Legrand E, Volney B, Lavergne A, Tournegros C, Florent L, Accrombessi $D$, Guillotte M, Puijalon OM, Esterre P: Molecular analysis of two local falciparum malaria outbreaks on the French Guiana coast confirms the msp1 B-K1/varD genotype association with severe malaria. Malar J 2005, 4:26.

24. Ekala M-T, Jouin H, Lekoulou F, Issifou S, Mercereau-Puijalon O, Ntoumi F: Plasmodium falciparum merozoite surface protein 1 (MSP1): genotyping and humoral responses to allele-specific variants. Acta Trop 2002, 81:33-46.

25. Ferreira MU, Kaneko O, Kimura M, Liu Q, Kawamoto F, Tanabe K: Allelic diversity at the merozoite surface protein-1 (MSP-1) locus in natural Plasmodium falciparum populations: a brief overview. Mem Inst Oswaldo Cruz 1998, 93:631-638.

26. Schoepflin S, Valsangiacomo F, Lin E, Kiniboro B, Mueller I, Felger I: Comparison of Plasmodium falciparum allelic frequency distribution in different endemic settings by high-resolution genotyping. Malar J 2009, 8:250.

27. Montoya L, Maestre A, Carmona J, Lopes D, Do Rosario V, Blair S: Plasmodium falciparum: diversity studies of isolates from two Colombian regions with different endemicity. Exp Parasitol 2003, 104:14-19.

28. Scopel KK, Fontes CJ, Nunes AC, Horta MF, Braga EM: Low sensitivity of nested PCR using Plasmodium DNA extracted from stained thick blood smears: an epidemiological retrospective study among subjects with low parasitaemia in an endemic area of the Brazilian Amazon region. Malar J 2004, 3:8.

29. Anderson TJ HB, Williams JT, Estrada-Franco JG, Richardson L, Mollinedo R, Bockarie M, Mokili J, Mharakurwa S, French N, Whitworth J, Velez ID, Brockman AH, Nosten F, Ferreira MU, Day KP: Microsatellites reveal a spectrum of population structre in the malaria parasite Plasmodium falciparum. Mol Biol Evol 2000, 17:1467-1482.

30. Anthony TG CD, Cox-Singh J, Matusop A, Ratnam S, Shamsul S, Singh B: Fragmented population structure of Plasmodium falciparum in a region of declining endemicity. J Infect Dis 2005, 191:1558-1564. 
31. Zwetyenga J, Rogier C, Tall A, Fontenille D, Snounou G, Trape JF, Mercereau-Puijalon O: No influence of age on infection complexity and allelic distribution in Plasmodium falciparum infections in Ndiop, a Senegalese village with seasonal, mesoendemic malaria. Am J Trop Med Hyg 1998, 59:726-735.

32. Mayor A, Saute F, Aponte JJ, Almeda J, Gómez-Olivé FX, Dgedge M, Alonso PL: Plasmodium falciparum multiple infections in Mozambique, its relation to other malariological indices and to prospective risk of malaria morbidity. Trop Med Int Health 2003, 8:3-11.

33. Vafa M, Troye-Blomberg M, Anchang J, Garcia A, Migot-Nabias F: Multiplicity of Plasmodium falciparum infection in asymptomatic children in Senegal: relation to transmission, age and erythrocyte variants. Malar J 2008, 7:17.

34. Zakeri S, Bereczky S, Naimi P, Pedro Gil J, Djadid ND, Farnert A, Snounou G, Bjorkman A: Multiple genotypes of the merozoite surface proteins 1 and 2 in Plasmodium falciparum infections in a hypoendemic area in Iran. Trop Med Int Health 2005, 10:1060-1064.

35. Branch OH, Takala S, Kariuki S, Nahlen BL, Kolczak M, Hawley W, Lal AA: Plasmodium falciparum genotypes, low complexity of infection, and resistance to subsequent malaria in participants in the Asembo Bay Cohort Project. Infect Immun 2001, 69:7783-7792.

36. Takala SL, Coulibaly D, Thera MA, Dicko A, Smith DL, Guindo AB, Kone AK, Traore K, Ouattara A, Djimde AA, Sehdev PS, Lyke KE, Diallo DA, Doumbo OK, Plowe CV: Dynamics of polymorphism in a malaria vaccine antigen at a vaccine-testing site in Mali. PLoS Med 2007, 4:e93.

37. Owusu-Agyei S, Smith T, Beck HP, Amenga-Etego L, Felger I: Molecular epidemiology of Plasmodium falciparum infections among asymptomatic inhabitants of a holoendemic malarious area in northern Ghana. Trop Med Int Health 2002, 7:421-428.

doi:10.1186/1756-3305-4-233

Cite this article as: Atroosh et al: Genetic diversity of Plasmodium falciparum isolates from Pahang, Malaysia based on MSP-1 and MSP-2 genes. Parasites \& Vectors 2011 4:233.

\section{Submit your next manuscript to BioMed Central and take full advantage of:}

- Convenient online submission

- Thorough peer review

- No space constraints or color figure charges

- Immediate publication on acceptance

- Inclusion in PubMed, CAS, Scopus and Google Scholar

- Research which is freely available for redistribution

Submit your manuscript at www.biomedcentral.com/submit 